\title{
AIDS-Related Anal Non-Hodgkin Lymphoma
}

National Cancer Institute

\section{Source}

National Cancer Institute. AIDS-Related Anal Non-Hodgkin Lymphoma. NCI Thesaurus. Code C7465.

A non-Hodgkin lymphoma arising from the anus and occurring in HIV-positive patients. Homosexual HIV-positive men have an increased risk of developing anal non-Hodgkin lymphoma in comparison to the general male population. The majority of the cases are large cell lymphomas of B-cell phenotype. 